\title{
DESIGN AND CRASH ANALYSIS OF A ROLLCAGE FOR FORMULA
} SAE RACE CAR

\author{
Mahendra H M ${ }^{1}$, B S Praveen Kumar ${ }^{2}$, Puttaswamaiah.S ${ }^{3}$, G.S Prakash ${ }^{4}$ \\ ${ }^{1}$ PG Scholar, Mechanical, East West Institute of Technology, Bangalore, Karnataka, India \\ ${ }^{2}$ Associate Professor, Mechanical, Don Bosco Institute of Technology, Bangalore, Karnataka, India \\ ${ }^{3}$ Assistant Professor, Mechanical, East West Institute of Technology, Bangalore, Karnataka, India \\ ${ }^{4}$ Professor, IEM Department, M S Ramaiah Institute of Technology, Bangalore, Karnataka, India
}

\begin{abstract}
The objective of this thesis is to analyze the design of the Formula SAE roll cage both analytical and by numerical methods. This analysis is based on the dynamic loads experienced by the roll cage under normal driving conditions, along with the torsional stiffness of the roll cage. A roll cage which is torsionally stiff enables a desirable roll moment distribution to be achieved for good handling balance. A roll cage which can absorb high energy impacts whilst controlling the rate of deceleration will increase the likelihood of drivers surviving a crash without injury. This work describes how a common model of the roll cage is developed using catia $v 5$ and Hyper Mesh to allow both linear and non-linear Finite Element Analysis to be performed by LS-DYNA software. The results from this analytical calculations will be used in future designs of Formula SAE roll cage, with the recommendations made that the future design incorporate stressed mild steel and carbon-fiber skins on a tubular space frame. This is in preparation for a future semi-monocoque design. Improvements for the testing procedures include a need for a lighter and more accurate car swing setup, along with a more rigid torsional test.
\end{abstract}

Keywords: Roll cage, Stiffness, Torsion, LS-DYNA, Tubular space frame

\section{INTRODUCTION}

Roll cage is widely used in vehicle design to give a support for all components. It has been study heavily to improve the performance of the car and create a suitable one for different type of vehicle. In the race car event, roll cage is built to boost it until a limit with the intention of win over challenger. Roll cage of a vehicle is usually designed with purpose to hold the load from the components of vehicle and mass from driver and passenger. Roll cage need to satisfy a number of requirements whose aims partly conflict because of different operating conditions which are loaded and unloaded weight, acceleration and braking force, level or uneven road and straight running or cornering. Nowadays, most of the components of vehicle are in the stage of replacing with Steel and aluminium materials. This is due to the properties of material that can be designed freely to hold the load from any direction. Its light-weight property makes it possible to enlarge the performance of the car while maintaining low weight. In the Formula SAE industry already widely used of steel, aluminium and composite materials and most of the part has been already replace with it. Thus, aluminium and steel material is highly important and it is worthy to study about it.

Presently, University Technical Malaysia Melaka (UTeM) had developed a racing Car using a roll cage made from the stainless steel [2]. However, this race car does not apply to The SAE standard. The roll cage system used now is tubular type. Thus, in order to Increase it performances and abide to the SAE standard, the new development of roll cage is needed. The idea is to optimize the characteristics of roll cage and hence, the Performance of the racing car by changing its different material is Steel grade IS3074, Aluminium alloy 6082T6 and SteelS275JRUNIEN10025.

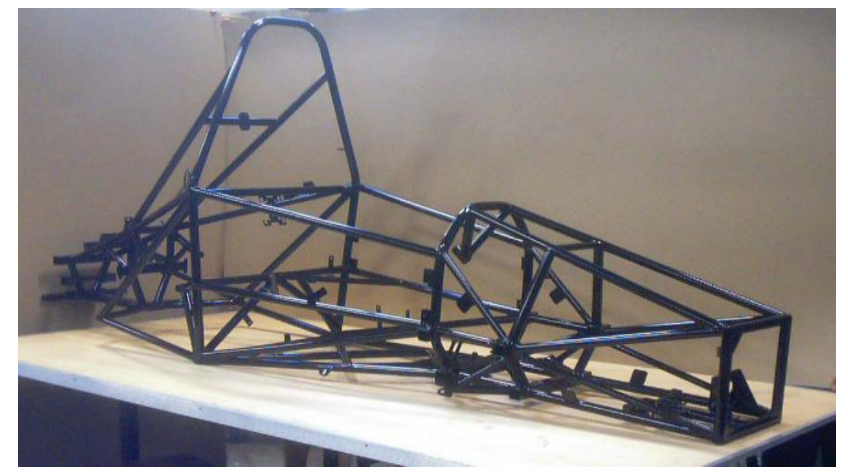

Fig 1: Stainless Steel Roll cage

\subsection{Objective of Study}

The purpose of the study is to design a tubular or space frame chassis by using CATIA V5 software, to achieve the crash analysis by the help of HYPERMESH and LS-DYNA software, and also the result are compared with different material (Steel grade IS3074, Aluminium alloy 6082T6 and Steel S275 JRUNIEN10025).

\subsection{Problem Statement}

The current racing car use tubular or space frame roll cage system built from stainless steel with diameter approximately $25 \mathrm{~mm}$. The complexity of design and the arrangement of the components contribute a waste space 
which not makes the car more compact. By using of stainless steel tubes has cause the overweight of the car and makes the car lose the power. Analysis on the chassis has not been done during development which is essential to know the load distribution and the strength of component during worst case scenario, it is impossible during troubleshooting and Optimization process in the future.

Therefore, this study will focus to reduce the problem occurred and make the Improvement of design. Steel grade IS3074, Aluminium alloy 6082T6 and SteelS275JRUNIEN10025. Will be used instead of stainless steel to solve the Overweight problem. As known that Steel grade IS3074, Aluminium alloy 6082T6 and SteelS275JRUNIEN10025 is a light weight material, good mechanical properties, cost effective anti corrosion, good energy absorption and quite hard for bending can be created to have a same strength as stainless steel. The analysis for acted load in static and dynamic condition will be determined to protect the driver during the worst case Situation. All the data will be documented for further study.

\section{METHODOLOGY}

The roll cage is a tabular design, which consists of rectangular and circular cross section being attached to a roll cage.

First the roll cage is modeled using CATIA v5 with available dimensions. There was a significant advantage in creating a model with the help of CATIA v5 that could be used for crash analyses.

Then the model was meshed using Hyper mesh. In order to reduce the complexity of the model, discrete element approximations were used where possible.

By using HYPERMESH as the pre-processor the resulting model could be exported to LS-DYNA using the built-in data interfaces.

The CRASH ANALYSIS required the common model to be modified by adding masses representing the wheels, engine and driver.

That beam elements are not sufficiently accurate to represent the steel tubing of the chassis in non-linear analysis: for this reason the beam elements were replaced by shell elements. Finally, a model of the impact-absorbing aluminium alloy, two grades of steel was added to the crash model for use in frontal and side impacts.

\subsection{Design Consideration for Rollcage}

Roll cage or the chassis frame is to provide the vehicle strength and structural integrity. The function of the space frame is to protect the driver (in case of serious impacts and rollover) and support front and rear suspension systems, engine, drive train, steering system and other systems in the vehicle, and must be of adequate strength to protect the operator in the event of a rollover or impact.
The objective of the frame design is to satisfy these functions while meeting the SAE regulations with special considerations given to safety of the occupants, ease of manufacturing, cost, quality, weight, and aesthetics. Moreover care has been taken to ensure that there are minimum welds on the frame pipes and maximum bends ensuring better strength and less cost of production of the vehicle. The roll cage must be constructed of steel tubing, with minimum dimensional and strength requirements dictated by SAE.

\subsection{Material and Size Optimization of Rollcage}

\section{Tubing}

According to rule book provided by SAE the minimum size of the steel tube should not be less than $25.4 \mathrm{~mm} \mathrm{X} 2.41 \mathrm{~mm}$. We have chosen Steel grade IS 3074, Aluminium alloy $6082 \mathrm{~T} 6$ and steel grade IS 3074 tubes with dimensions of $28.6 \mathrm{~mm}$ X $2.1 \mathrm{~mm}$ (front impact and side impact).

\subsubsection{For Front Impact}

Baseline Steel $25.4 \mathrm{~mm}$ outer diameter, inner diameter $20.59 \mathrm{~mm}$ and $2.41 \mathrm{~mm}$ wall thickness.

Buckling modulus = EI (Young's Modulus*Moment of Inertia)

$$
\begin{array}{ll} 
& =\pi / 64\left(\mathrm{~d}_{\mathrm{o}}{ }^{4}-\mathrm{d}_{\mathrm{i}}{ }^{4}\right) \\
& =\pi / 64\left(25.4^{4}-20.59^{4}\right) \\
& =11626 \mathrm{~mm}^{4} \\
& =11626 \mathrm{E}
\end{array}
$$

Considering Steel $28.6 \mathrm{~mm}$ outer diameter, inner diameter $24.4 \mathrm{~mm}$ and $2.1 \mathrm{~mm}$ wall thickness

Buckling modulus = EI (Young's Modulus*Moment of Inertia)

$$
\begin{array}{ll} 
& =\pi / 64\left(\mathrm{~d}_{\mathrm{o}}{ }^{4}-\mathrm{d}_{\mathrm{i}}^{4}\right) \\
& =\pi / 64\left(28.6^{4}-24.4^{4}\right) \\
& =15443 \mathrm{~mm}^{4} \\
\text { Hence B M } & =15443 \mathrm{E}
\end{array}
$$

In front impact therefore considering steels stiffer than the baseline steel.

\subsubsection{For Side Impact}

Baseline Steel $25.4 \mathrm{~mm}$ outer diameter, inner diameter $20.59 \mathrm{~mm}$ and $2.41 \mathrm{~mm}$ wall thickness.

Buckling modulus = EI (Young's Modulus*Moment of Inertia)

$$
\begin{array}{ll} 
& =\pi / 64\left(\mathrm{~d}_{\mathrm{o}}{ }^{4}-\mathrm{d}_{\mathrm{i}}{ }^{4}\right) \\
& =\pi / 64\left(25.4^{4}-20.59^{4}\right) \\
& =11626 \mathrm{~mm}^{4} \\
\text { Hence B M } & =11626 \mathrm{E}
\end{array}
$$


Considering Steel with $28.6 \mathrm{~mm}$ outer diameter, inner diameter $24.4 \mathrm{~mm}$ and $2.5 \mathrm{~mm}$ wall thickness

Buckling modulus = EI (Young's Modulus*Moment of Inertia)

Hence B M

$$
\begin{aligned}
& =\pi / 64\left(\mathrm{~d}_{\mathrm{o}}{ }^{4}-\mathrm{d}_{\mathrm{i}}{ }^{4}\right) \\
& =\pi / 64\left(28.6^{4}-24.4^{4}\right) \\
& =15443 \mathrm{~mm}^{4} \\
& =15443 \mathrm{E}
\end{aligned}
$$

In side impact therefore considering steels stiffer than the baseline steel.

\subsection{Material Selection}

The selection of material to construct a roll cage. Availability is one of the factors which dominate the material selection process. Working on this single aspect, list of different desirable and available materials was prepared. Steel and aluminium alloys are always the choice of most of the designer. After reviewing mechanical properties, availability, cost and other significant factors, following material was selected.

$>\quad$ Steel S275JR UNI EN 10025(Fe430)

$>$ Aluminium alloy 6082T6

$>\quad$ steel grade IS 3074

\begin{tabular}{|l|l|l|l|l|}
\hline MATERIAL & E (MPa) & $\begin{array}{l}\text { POISS } \\
\text { ON } \\
\text { RATIO }\end{array}$ & $\begin{array}{l}\text { DENSIT } \\
\text { Y } \\
\left(\mathrm{g} / \mathrm{mm}^{3}\right)\end{array}$ & $\begin{array}{l}\text { YIEL } \\
\text { D } \\
(\mathrm{MPa})\end{array}$ \\
\hline Steel IS 3074 & 200000 & 0.266 & $7.86 * 10-3$ & 373 \\
\hline Al 6082T6 & 70000 & 0.33 & $2.7 * 10-3$ & 428.5 \\
\hline $\begin{array}{l}\text { Steel S275 } \\
\text { JRUNIEN10 } \\
\text { 025 } \\
(\text { Fe430) }\end{array}$ & 206000 & 0.3 & $7.8 * 10-3$ & 275 \\
\hline
\end{tabular}

\section{DATA INPUT AND ANALYSIS}
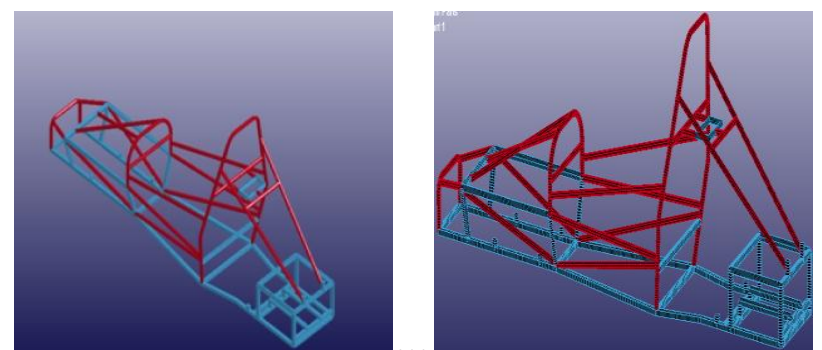

Fig 3.1 CATIA Model

Fig 3.2: Hyper Mesh Model
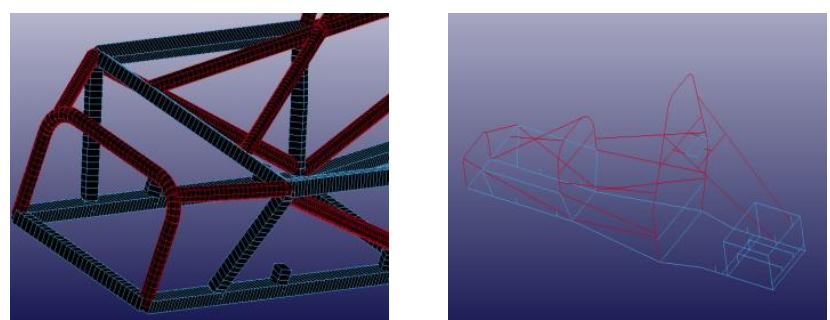

Fig 3.3: Shell Element Model Fig 3.4: LS DYNA Model (The LS DYNA model having two beams they are: BEAM 1 \& BEAM 2)

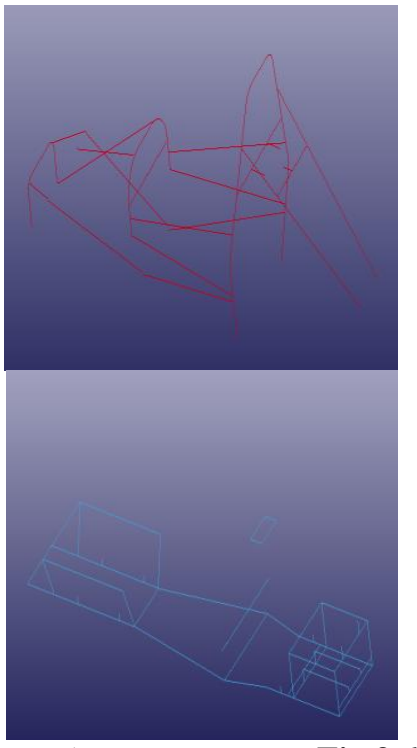

Fig 3.5: Beam 1

Fig 3.6: Beam 2

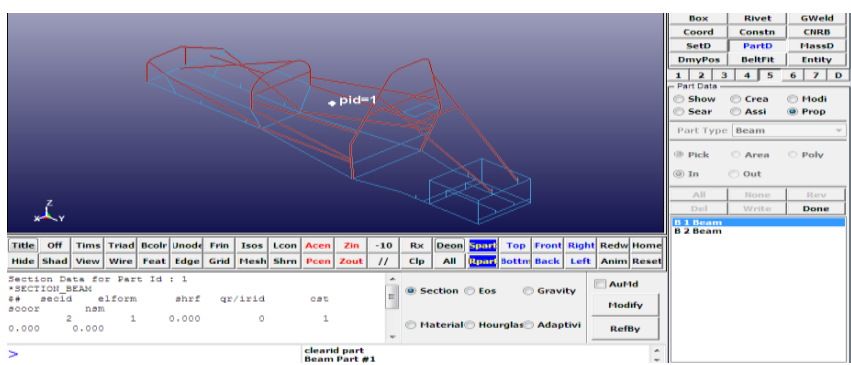

Fig 3.7: Verify Material and Section Properties
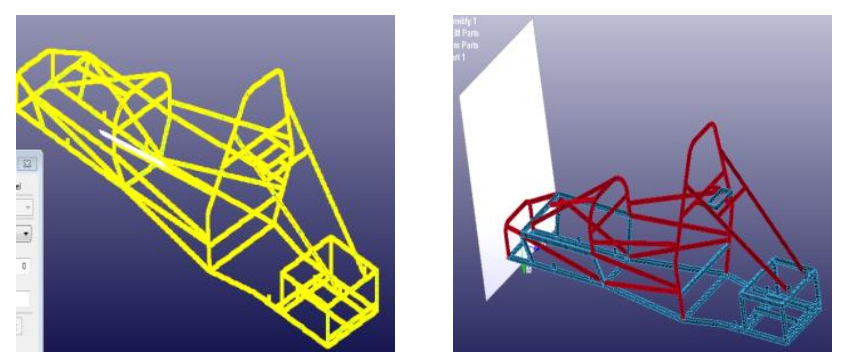

3.8: Velocities to the Roll cage Fig 3.9: Rigid Wall and Model
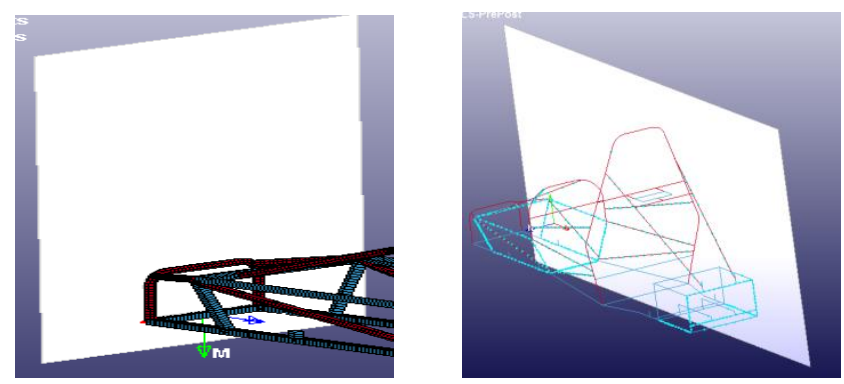

Fig 3.10: Contact in Front Impact Fig 3.11: Contact in Side Impact 


\section{RESULT, OPTIMISATION AND DISCUSSION}

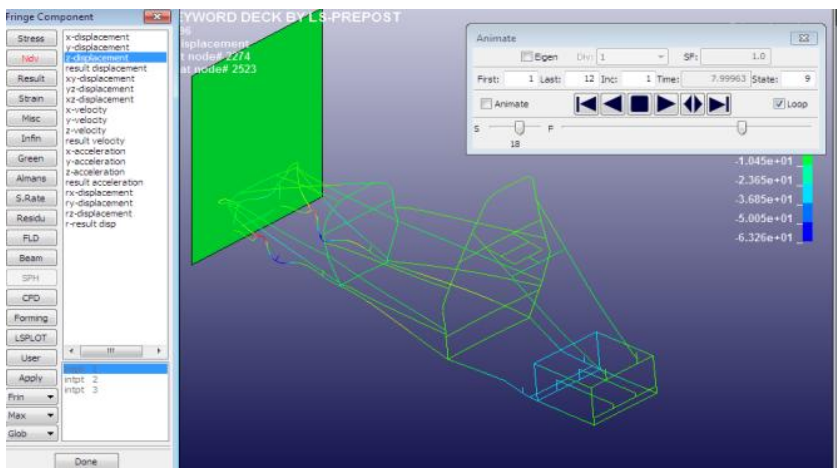

Fig 4.1: Model of Roll cage during Impact

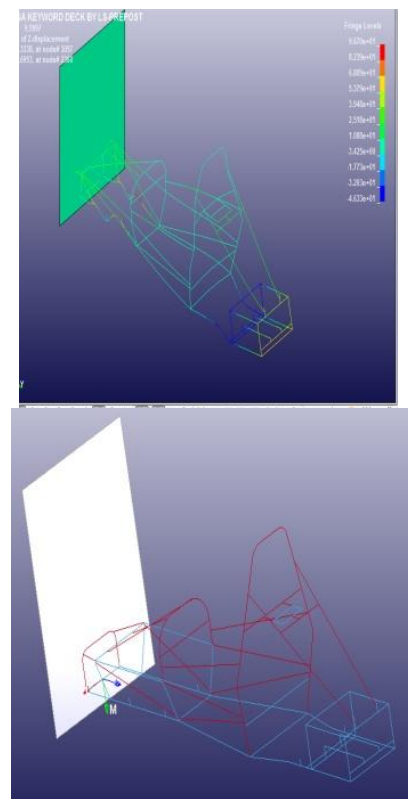

Fig 4.2: Result of the Front Impact

Table 4.1: Different Material

\begin{tabular}{|l|l|}
\hline SL.NO & MATERIAL \\
\hline A & Steel grade IS 3074 \\
\hline B & Aluminium alloy 6082T6 \\
\hline C & SteelS275JRUNIEN10025 (Fe430) \\
\hline
\end{tabular}

\subsection{Optimization for Frontal Impact Safety}
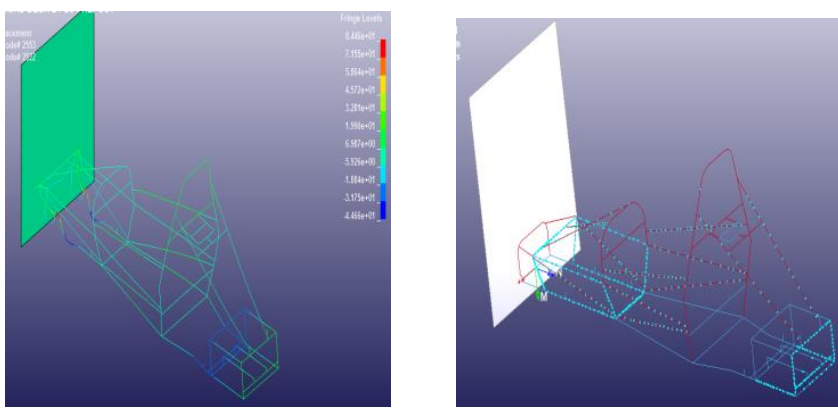

Fig 4.3: Optimization for Fontal Impact Safety
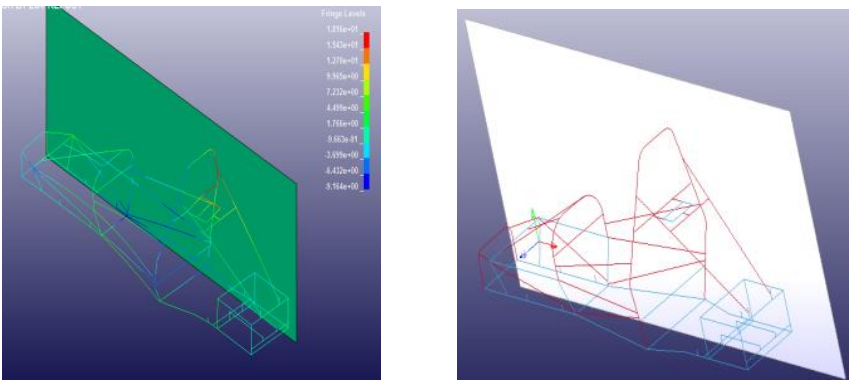

Fig 4.4: Result from Side Impact

\subsection{Optimization for Side Impact Safety}
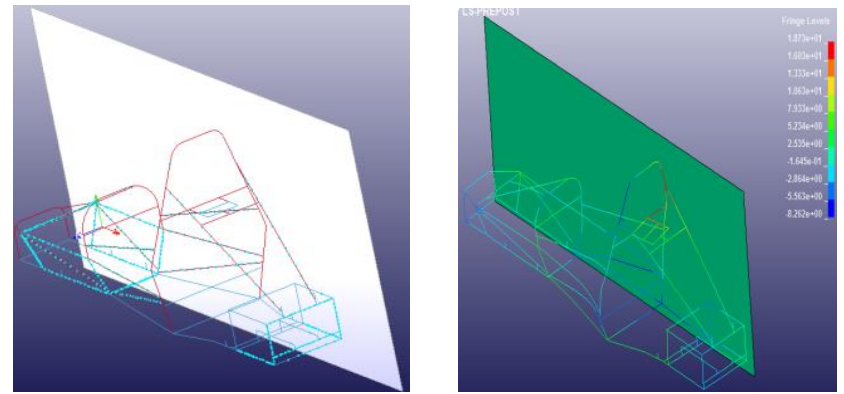

Fig 4.5: Optimization for Side Impact Safety

\section{CONCLUSIONS}

In the project is presented a detailed analysis of the crash behavior of the front and side impact rollcage structure that was designed to equip the formula SAE car. The simulations performed by the finite element methods reveal some very important Facts.

The design of the roll cage is improve driver safety by optimizing the roll cage by add and variation of mass in roll cage using L S -DYNA software.

The design and position of the links between the energy absorbing structure and the car frame structure are found to be essential to determine the crash worthiness of the vehicle in case of front impact and side impact.

In terms of internal energy, kinetic energy and total energy, Steel IS grade 3074 has better energy absorbing capabilities than the other two materials.

In terms of total internal energy, total kinetic energy, Steel IS grade 3074 has better energy absorbing capabilities than the other two materials.

In terms of rigid wall force, Steel IS grade 3074 has better force absorbing capabilities than the other two materials.

After comparison between the three materials (Steel IS grade 3074, Aluminium $6082 \mathrm{T6}$ and Steel S275) we can conclude that Steel IS grade 3074 is better for design a roll cage to provide a driver safety in front and side crash than the other two materials. 


\section{REFERENCES}

[1] Design/Build Of A Formula SAE Vehicle (L.Y Chan, M. Doecke, H. Lalwani, H.W Lau, T. Lau, C.C Lee, C.C Low.)

[2] Numerical And Experimental Analysis Of Formula SAE Chassis, With Recommendations For Future Design Iterations ( The University Of Queensland)

[3] Torsional Chassis Stiffness And Crashworthiness Analysis Of The University Of Leeds (2000 Formula SAE / Student Racing Car)

[4] Design Of The Impact Attenuator For A Formula Student Racing Car: Numerical Simulation Of The Impact Crash Test (Mechanical Engineering Department, Politecnico Di Torino, Corso Duca Degli Abruzzi24, 10129 Torino, Italy)

[5] Introduction To Formula SAE Suspension And Frame Design Edmund F. Gaffney Iii And Anthony R. Salinas

[6] 2010 Formula SAE Rules, SAE International, USA. 